\title{
Effect of Clopidogrel with or without Omeprazole in Patients with Carotid Artery Stenting

\author{
B Ma ${ }^{1}$, L Hang ${ }^{2}$, G Chen ${ }^{1}, \mathrm{Y} \mathrm{Du}^{1}$
}

\begin{abstract}
Background: Recent concerns have been raised about the potential for proton pump inhibitors (PPIs) to blunt the efficacy of clopidogrel. We observed the effect of clopidogrel plus aspirin with or without omeprazole in patients with carotid stenoses after they received placement of carotid stents.

Methods: Sixty-four consecutive patients treated with percutaneous carotid artery stenting (CAS) comprised the sample. All enrolled patients underwent the $C^{13}$ urea breath test $\left(C^{13} U B T\right)$ before CAS. Patients with Helicobacter pylori infection and a history of peptic ulcer were assigned dual antiplatelet combination with omeprazole. Others received dual antiplatelet without omeprazole. Transcranial Doppler and ultrasonography were performed to assess the middle cerebral artery and carotid artery in follow-up at three months and six months.

Results: Eight patients had gastrointestinal bleeding; the event rate was $22.6 \%$ without omeprazole and $3.8 \%$ with omeprazole. The rate of gastrointestinal bleeding was reduced with omeprazole as compared without omeprazole $(\mathrm{p}=0.026, \mathrm{p}<0.05)$. The two groups did not differ significantly in the rate of instent restenosis and thrombus through transcranial Doppler and ultrasonography.

Conclusion: Among patients receiving dual antiplatelet therapy, prophylactic use of omeprazole reduced the rate of upper gastrointestinal bleeding. There was no apparent interaction between clopidogrel and omeprazole in patients with carotid artery stenting.
\end{abstract}

Keywords: Carotid artery stenting, clopidogrel, omeprazole, proton pump inhibitors

\section{Efecto del Clopidogrel con o sin Omeprazol en Pacientes con Stent en la Arteria Carótida}

$\mathrm{B} \mathrm{Ma}^{1}, \mathrm{~L} \mathrm{Hang}^{2}$, G Chen ${ }^{1}, \mathrm{Y} \mathrm{Du}{ }^{1}$

\begin{abstract}
RESUMEN
Antecedentes: Recientemente se han expresado preocupaciones acerca de la posibilidad de que los inhibidores de la bomba de protones (IBP) para debilitar la eficacia del clopidogrel. Observamos el efecto del clopidogrel más aspirina con o sin omeprazol en pacientes con estenosis de la arteria carótida después de que recibieran la colocación de stents carotídeos.

Métodos: Sesenta y cuatro pacientes consecutivos tratados con stent percutáneo de la arteria carótida (SAC) fueron seleccionados para formar la muestra. A todos los pacientes inscritos se les realizó la prueba de aliento con urea $C^{13}\left(C^{13} U B T\right)$ antes de CAS. A pacientes con infección por Helicobacter pylori y antecedentes de úlcera péptica les fue asignada una combinación antiplaquetaria dual con omeprazol. Otros recibieron tratamiento antiplaquetario dual sin omeprazol. Se realizaron una prueba Transcranial Doppler y una ultrasonografía a fin de evaluar la arteria cerebral media y la arteria carótida en seguimientos a los tres meses y a los seis meses.

Resultados: Ocho pacientes tuvieron hemorragia gastrointerstinal; la tasa de eventos fue $22.6 \%$ sin omeprazol y 3.8\% con omeprazol. La tasa de hemorragia gastrointerstinal se redujo con omeprazol en comparación con la obtenida sin omeprazol $(\mathrm{p}=0,026, \mathrm{p}<0.05)$. Los dos grupos no difirieron significativamente con respecto a la tasa de restenosis en stent y trombos a través de la prueba Transcranial Doppler y la ultrasonografia.
\end{abstract}

From: ${ }^{1}$ Department of Neurology and ${ }^{2}$ Department of Gastroenterology, Affiliated Hospital of Ningxia Medical University, Yinchuan, China.
Correspondence: Dr LY Hang, Department of Gastroenterology, Affiliated Hospital of Ningxia Medical University, Yinchuan, Ningxia Hui Autonomous Region 750004, China. E-mail: txmbw@126.com 
Conclusión: Entre los pacientes que reciben terapia antiplaquetaria dual, el uso profiláctico de omeprazol redujo la tasa de hemorragia gastrointestinal superior. No hubo interacción ostensible entre el clopidogrel y el omeprazol en pacientes con stent de la arteria carótida.

Palabras clave: Stent de la arteria carótida, omeprazol, clopidogrel, inhibidores de la bomba de protones

West Indian Med J 2013; 62 (2): 136

\section{INTRODUCTION}

Percutaneous carotid artery stenting (CAS) for stenoses of the internal carotid artery (ICA) has the potential of being minimally invasive, less traumatic and safer in patients with high surgical risk than carotid endarterectomy $(1,2)$. Carotid artery stenting provides a safe and reasonable revascularization alternative in patients with symptomatic carotid artery disease. The main complications after stent placement are thrombus and restenosis of the stented artery, which may require revascularization procedures. In-stent restenosis (ISR) continues to be a concern, with angiographic and clinical restenosis rates reported to be $10-15 \%(3,4)$. Several factors have been associated with an increased risk of restenosis, including long and multiple stents, stent malapposition and lack of dual antiplatelet drugs. Furthermore, the embolization of plaque fragments has generated concern regarding the safety and wisdom of CAS and transcranial Doppler (TCD) studies have indicated the occurrence of emboli associated with CAS (5). Antithrombotic drugs are used during the acute management of carotid intervention. In patients with carotid artery stents, aspirin and clopidogrel, dual antiplatelet treatment, is prescribed to reduce the risks of thromboemboli and in-stent restenosis.

The risks of antiplatelet drugs are associated with gastrointestinal haemorrhage which is the most common serious bleeding complication from the use of long-term antiplatelet therapy $(6,7)$. Proton pump inhibitors (PPIs) have been advocated to reduce the gastrointestinal haemorrhage risk in CAS patients with oral dual antiplatelet, aspirin and clopidogrel $(8,9)$. Recent studies have shown inhibition of the antiplatelet effect of clopidogrel by PPIs most consistently $(10,11)$. Therefore, some studies believe the combination of antiplatelet and PPIs could lead to the risk of adverse cardiovascular accident $(12,13)$. In this study, we observed the effect of clopidogrel plus aspirin with or without omeprazole in patients with carotid stenoses after they received carotid stenting placement and assessed the efficacy and safety of concomitant administration of clopidogrel and omeprazole in CAS patients.

\section{SUBJECTS AND METHODS}

The study population consisted of 64 patients with CAS who were managed in the Department of Neurology in the Affiliated Hospital of Ningxia Medical University from January 2009 to March 2011. The average age was $55.16 \pm$ 8.38 years; $68 \%$ was male. All enrolled patients underwent the $\mathrm{C}^{13}$ urea breath test ( $\left.\mathrm{C}^{13} \mathrm{UBT}\right)$ to detect Helicobacter pylori before CAS. Patients with positive infection were advised to undergo $H$ pylori eradication therapy and all agreed. The patients who had $H$ pylori infection and history of peptic ulcer were assigned to take dual antiplatelets (clopidogrel $75 \mathrm{mg}$ /daily and enteric-coated aspirin 100 $\mathrm{mg} /$ daily) with omeprazole $20 \mathrm{mg} /$ daily. The patients who had no $H$ pylori infection were only assigned to take dual antiplatelets (clopidogrel $75 \mathrm{mg} /$ daily and enteric-coated aspirin $100 \mathrm{mg} /$ daily). Clinical follow-up was conducted at three months and six months. All patients underwent TCD to observe the middle cerebral artery (MCA) and ultrasound to observe the carotid artery. In the omeprazole group, one patient underwent computed tomography angiography (CTA) and TCD at six months after CAS, one patient underwent digital subtraction angiography (DSA) and TCD at six months after CAS. All patients gave written informed consent, and the study protocol was approved by the hospital ethics committee and the Ningxia committee on research ethics for the protection of human subjects.

Quantitative variables are described as mean $\pm \mathrm{SD}$. Categorical variables are presented as numbers and percentages. Comparisons of quantitative variables were performed by independent-sample $t$-test analysis for normally distributed variables. SPSS 15.0 package programme (SPSS, Chicago, IL, USA) was used for data analysis. A probability value of $<0.05$ was considered to indicate statistical significance.

\section{RESULTS}

Seven patients did not continue follow-up for personal reasons. Twenty-three patients had $H$ pylori infection by $\mathrm{C}^{13}$ UBT. There were 26 in the clopidogrel and aspirin group with omeprazole (23 patients had $H$ pylori infection, five patients had history of peptic ulcer, two patients had both $H$ pylori infection and history of peptic ulcer) and 31 in the clopidogrel and aspirin group without omeprazole. The two study groups were well matched with respect to baseline characteristics. There were eight gastrointestinal bleeding events: melaena and positive fecal occult blood were present in these patients. There was also a significant reduction in the number of patients with investigator-defined gastrointestinal bleeding events with omeprazole (26 patients) as compared without omeprazole (Fig. 1).

Fifty-seven patients underwent TCD at three months and six months after CAS. We used mean velocity (MV) and 


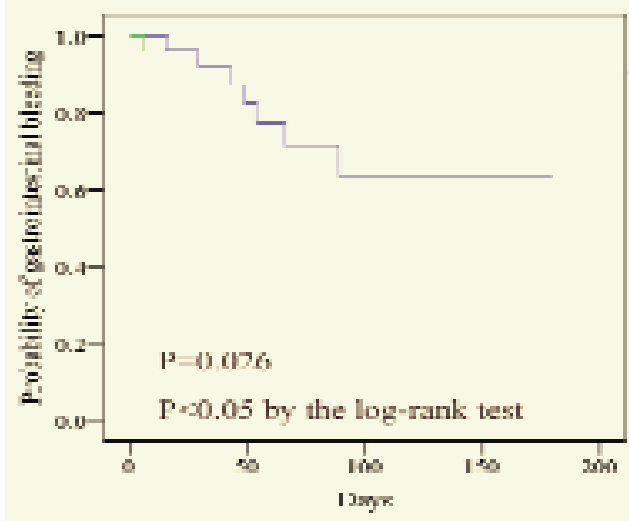

whthost cenfrazole wuth comeprazole

Fig. 1: Kaplan-Meier estimates of the probability of gastrointestinal bleeding events.

pulsatility index (PI) to assess the MCA. One patient underwent CTA and TCD at six months after CAS (Fig. 2) without

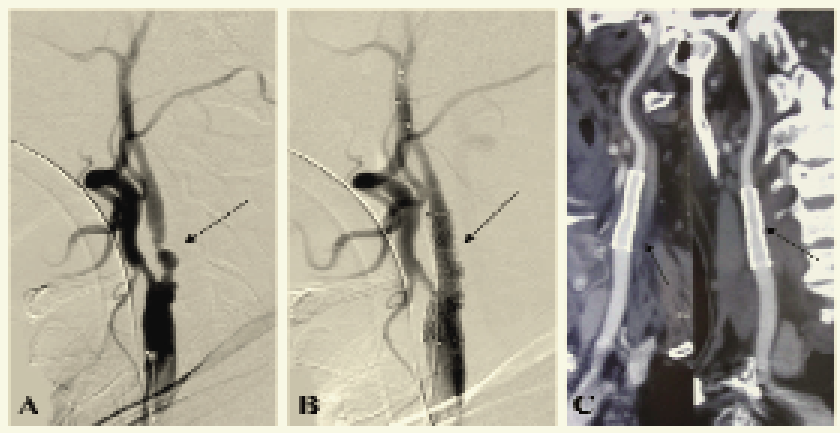

Fig. 2: A 56-year old man with a left hemispheric ischaemic stroke. (A) Pre-stenting digital subtraction angiography (DSA) reveals stenosis of the right internal carotid artery. (B) DSA shows the right internal carotid artery after instant stenting placement. (C) Computed tomography angiography (CTA) shows the right internal carotid artery after stenting placement at six months.

omeprazole. One patient underwent DSA and TCD at six months after CAS (Fig. 3) without omeprazole. From CTA
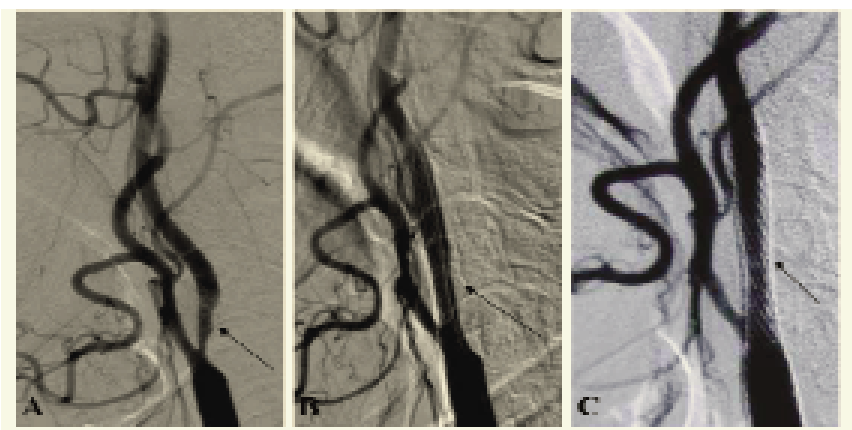

Fig. 3: A 60-year old man with a left hemispheric ischaemic stroke. (A) Pre-stenting digital subtraction angiography (DSA) reveals stenosis of the right internal carotid artery. (B) DSA showed the right internal carotid artery after instant stenting placement. (C) DSA showed the right internal carotid artery after stenting placement at six months. and DSA, we did not observe apparent carotid artery in-stent restenosis. At the same time, signals of TCD were harmonic in tone and of relatively normal spectrum. There was no statistical significance in these two groups by TCD $(p>$ 0.05), [Table 1, Fig. 4].

Table 1: The transcranial Doppler of the follow-up at three months and six months after carotid artery stenting

\begin{tabular}{lccccc}
\hline & $\begin{array}{c}\text { Follow-up } \\
\text { time (month) }\end{array}$ & $\begin{array}{c}\text { Without } \\
\text { omeprazole }\end{array}$ & $\begin{array}{c}\text { With } \\
\text { omeprazole }\end{array}$ & F & $\boldsymbol{p}$ \\
\hline MV & 3 & $99.15 \pm 1.40$ & $97.39 \pm 1.52$ & 0.031 & 0.860 \\
& 6 & $97.42 \pm 1.92$ & $95.30 \pm 1.14$ & 0.433 & 0.513 \\
PI & 3 & $0.95 \pm 0.15$ & $0.93 \pm 0.11$ & 2.988 & 0.090 \\
& 6 & $0.93 \pm 0.09$ & $0.93 \pm 0.10$ & 0.504 & 0.481 \\
\hline
\end{tabular}

$\mathrm{MV}=$ mean velocity, $\mathrm{PI}=$ pulsatility index

A
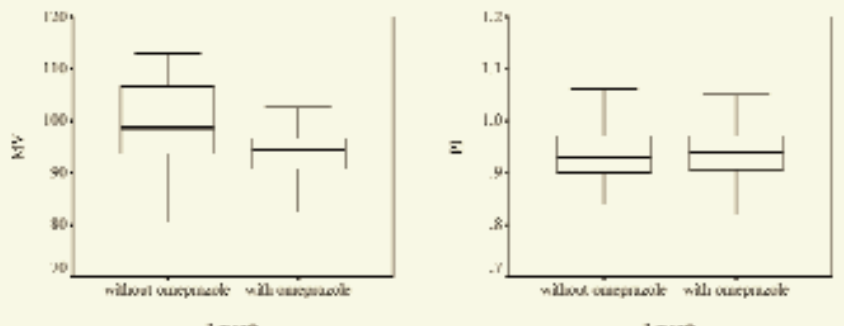

B
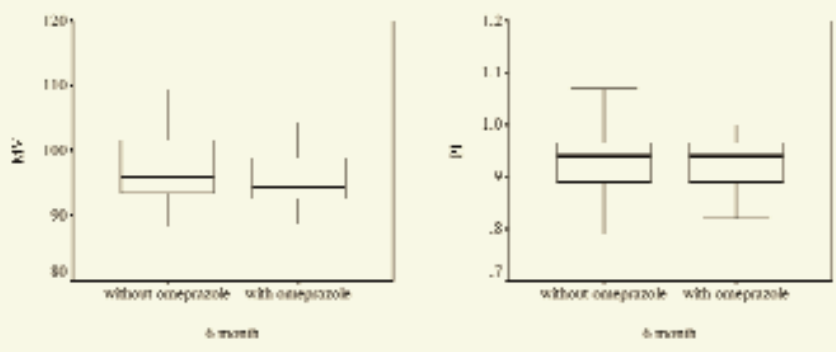

Fig. 4: The mean velocity (MV) and pulsatility index (PI) of transcranial Doppler with follow-up at three months and six months after carotid artery stenting.

Fifty-seven patients underwent ultrasound at three months and six months after CAS. We used peak systolic velocity (PSV) to assess the internal carotid artery (ICA). We did not observe apparent thrombus in the carotid artery. At the same time, there was no statistical significance in these two groups by ultrasound ( $p>0.05$ ), [Table 2, Fig. 5]. 
Table 2: The peak systolic velocity (PSV) of ultrasound with follow-up at three months and six months after carotid artery stenting

\begin{tabular}{lccccc}
\hline & $\begin{array}{c}\text { Follow-up } \\
\text { time (month) }\end{array}$ & $\begin{array}{c}\text { Without } \\
\text { omeprazole }\end{array}$ & $\begin{array}{c}\text { With } \\
\text { omeprazole }\end{array}$ & F & p \\
\hline PSV & 3 & $93.32 \pm 25.79$ & $101.65 \pm 11.53$ & 0.95 & 0.13 \\
& 6 & $100.48 \pm 18.14$ & $100.54 \pm 20.19$ & 0.31 & 0.99 \\
\hline
\end{tabular}

PSV $=$ peak systolic velocity
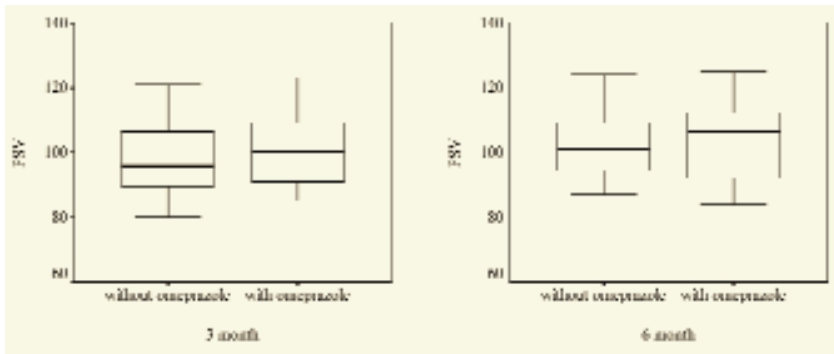

Fig. 5: The peak systolic velocity (PSV) of ultrasound of the follow-up at three months and six months after carotid artery stenting.

\section{DISCUSSION}

A meta-analysis of five randomized clinical trials demonstrated that combination therapy with aspirin plus clopidogrel is associated with reductions in all-cause and cardiovascular mortality in patients who present with ST-segment elevation myocardial infarction as well as modest reductions in myocardial infarction or stroke in patients (14). Therefore, clopidogrel has become the second most commonly used prescription drug worldwide $(15,16)$. Clopidogrel alone, aspirin alone, and their combination are all associated with increased risk of gastrointestinal bleeding (17). The risk of gastrointestinal bleeding is increased in people taking dual antiplatelet drugs. Bleeding can occur at any site in the gastrointestinal tract, but it is most common in the upper gastrointestinal tract. A large case-control study to evaluate upper gastrointestinal bleeding in patients using single and dual antiplatelet drugs in the Danish population found an odds ratio for bleeding of 1.8 in people taking low dose aspirin alone, 1.1 in those taking clopidogrel alone and 7.4 in those taking both (18). Gastrointestinal bleeding was an important correlate of premature antiplatelet therapy cessation, and $20.8 \%$ of patients with gastrointestinal bleeding were discharged without aspirin or thienopyridine therapy (19). Patients who had gastrointestinal bleeding usually presented with vomiting blood, passing dark tarry stools or melaena, upper abdominal symptoms and postural dizziness. In this study, patients presented with only melaena. Clinical characteristics that increase the risk of gastrointestinal bleeding include advanced age, concurrent use of anticoagulants, steroids or nonsteroidal anti-inflammatory drugs (NSAIDs) including aspirin, and $H$ pylori infection. A history of peptic ulcer disease was an independent predictor of risk for gastrointestinal bleeding in patients treated with dual antiplatelet therapy (20). Longer term risks were related to oral dual antiplatelets, usually aspirin and clopidogrel. Increased dose and duration of dual antiplatelet treatment are also likely to affect the risk of upper gastrointestinal bleeding. The risk of gastrointestinal bleeding increases as the number of risk factors increase (17).

Studies have shown that platelet aggregation and blood coagulation are optimal at $\mathrm{pH}$ 7.4. Below $\mathrm{pH}$ 5.9, platelet aggregation, the initial step of haemostasis, is practically non-existent (21). Only PPIs can reliably achieve such values if sufficient doses are given. Guidelines recommend that patients taking dual antiplatelet drugs who are at high risk of upper gastrointestinal bleeding (as outlined above) should be co-prescribed PPIs, because of their considerable gastroprotective effect. Proton pump inhibitors should be continuously available in the circulation to inhibit newly generated pumps and thereby inhibit gastric acidity for prolonged periods. Therefore, PPIs play an important role in treatment of gastrointestinal bleeding. This study also showed a significant reduction in the risk of gastrointestinal clinical events, including overt upper gastrointestinal bleeding, in patients receiving dual antiplatelet therapy who also received omeprazole. Clopidogrel is a prodrug, which requires conversion by the liver primarily via CYP3A4 and CYP2C19 to an active metabolite, which irreversibly binds to the platelet adenosine diphosphate receptor, thereby inhibiting platelet aggregation $(22,23)$. Proton pump inhibitors are metabolized by the hepatic cytochrome P-450 system, predominantly CYP2C19 (24). The major site of drug-drug interaction between clopidogrel and PPIs appears to involve the CYP2C19 isoenzyme pathway. Concomitant use of PPIs may competitively inhibit activation of clopidogrel by CYP2C19, thereby attenuating its antiplatelet effect.

Transcranial Doppler may be used by clinicians as a noninvasive screening tool for the diagnosis of intracranial arterial stenosis. Data regarding the sensitivity and specificity of TCD in the diagnosis of MCA have been published. Ultrasound is noninvasive, rapid and relatively inexpensive and should be an excellent modality for the assessment of results after placement of a carotid artery stent. In this study, we used TCD and ultrasound to assess carotid artery and MCA after the carotid artery stent placement. We assigned patients, who had $H$ pylori infection and a history of peptic ulcer, to receive dual antiplatelet with omeprazole. The result that patients receiving omeprazole with clopidogrel plus aspirin had no more thromboemboli and carotid artery stent restenosis than those receiving clopidogel plus aspirin alone suggests that the potential interaction between omeprazole and clopidogrel is safe. There was no significant difference in tone and the distribution and appearance of the spectrum of TCD in these two groups with or without omeprazole. The results of TCD showed that MV and PI of the MCA were not 
different at three months and six months. Furthermore, there was no apparent thrombus in the carotid artery by ultrasound. This study did not show any significant increases in the risk of thromboemboli and in-stent restenosis with concomitant use of clopidogrel and omeprazole. Although previous observational studies have yielded conflicting results in this regard, the current study reveals no harm from concomitant clopidogrel and omeprazole use. This study sample with CAS was small; estimates of risk can be extrapolated from other studies.

After all, small pharmacodynamic studies have indicated a potential influence of PPIs on the antiplatelet effects of clopidogrel. As the plasma half-lives of both clopidogrel and omeprazole are short (1-2 hours), the potential for drugdrug competition at either the P-glycoprotein or CYP2C19 level may be attenuated by separating the timing of clopidogrel and omeprazole administration (25). Therefore, we suggest that "dose separation" strategy may diminish advantage during the co-administration of clopidogrel and omeprazole.

In conclusion, patients with carotid artery stent placement who were receiving dual antiplatelet therapy had a significant reduction in gastrointestinal bleeding with omeprazole use as compared without omeprazole. Furthermore, our small, single-centre study suggests that there was no effect of concomitant use of omeprazole and clopidogrel on antiplatelet inhibition. Concomitant use of omeprazole in patients who were receiving dual antiplatelet aspirin and clopidogrel after CAS is safe and feasible.

\section{REFERENCES}

1. Forbes TL. Preliminary results of carotid revascularization endarterectomy $v s$ stenting trial (CREST). J Vasc Surg 2010; 51: 1300-01.

2. Brott TG, Hobson RW, Howard G, Roubin GS, Clark WM, Brooks W et al. Stenting versus endarterectomy for treatment of carotid-artery stenosis. N Engl J Med 2010; 363: 11-23.

3. Clark MA, Bakhai A, Pelletier EM, Cohen DJ. Clinical and economic effects of coronary restenosis after percutaneous coronary intervention in a managed care population. Manag Care 2005; 14: 46-51.

4. Cohen DJ, Houser F, Mack M, Simon AW, Battaglia SL, Tarkington LG et al. Practice and outcomes of percutaneous coronary intervention in the community before drug-eluting stents: a report from the HCA database. J Invasive Cardiol 2003; 15: 121-7.

5. Jordan WJ, Voellinger DC, Doblar DD, Plyushchevat NP, Fisher WS, McDowell HA. Microemboli detected by transcranial Doppler monitoring in patients during carotid angioplasty versus carotid endarterectomy. Cardiovasc Surg 1999; 7: 33-6.

6. Bhatt DL, Scheiman J, Abraham NS, Antman EM, Chan FK, Furberg C et al. ACCF/ACG/AHA 2008 expert consensus document on reducing the gastrointestinal risks of antiplatelet therapy and NSAID use. Am J Gastroenterol 2008; 103: 2890-907.

7. Moukarbel GV, Signorovitch JE, Pfeffer MA, McMurray JJ, White HD, Maggioni AP et al. Gastrointestinal bleeding in high risk survivors of myocardial infarction: the VALIANT Trial. Eur Heart J 2009; 30: 2226-32.

8. Lai KC, Lam SK, Chu KM, Wong BC, Hui WM, Hu WH et al. Lansoprazole for the prevention of recurrences of ulcer complications from long-term low-dose aspirin use. N Engl J Med 2002; 346: 2033-8.
9. Chan FK, Chung SC, Suen BY, Lee YT, Leung WK, Leung VK et al. Preventing recurrent upper gastrointestinal bleeding in patients with Helicobacter pylori infection who are taking low-dose aspirin or naproxen. N Engl J Med 2001; 344: 967-73.

10. Sibbing D, Morath T, Stegherr J, Braun S, Vogt W, Hadamitzky M et al. Impact of proton pump inhibitors on the antiplatelet effects of clopidogrel. Thromb Haemost 2009; 101: 714-9.

11. Gilard M, Arnaud B, Cornily JC, Le Gal G, Lacut K, Le Calvez G et al. Influence of omeprazole on the antiplatelet action of clopidogrel associated with aspirin: the randomized, double-blind OCLA (Omeprazole CLopidogrel Aspirin) study. J Am Coll Cardiol 2008; 51: 256-60.

12. Ho PM, Maddox TM, Wang L, Fihn SD, Jesse RL, Peterson ED et al. Risk of adverse outcomes associated with concomitant use of clopidogrel and proton pump inhibitors following acute coronary syndrome. JAMA 2009; 301: 937-44.

13. Shi S, Klotz U. Proton pump inhibitors: an update of their clinical use and pharmacokinetics. Eur J Clin Pharmacol 2008; 64: 935-51.

14. Helton TJ, Bavry AA, Kumbhani DJ, Duggal S, Roukoz H, Bhatt DL. Incremental effect of clopidogrel on important outcomes in patients with cardiovascular disease: a meta-analysis of randomized trials. Am J Cardiovasc Drugs 2007; 7: 289-97.

15. Mehta SR, Yusuf S, Peters RJ, Bertrand ME, Lewis BS, Natarajan MK et al. Effects of pretreatment with clopidogrel and aspirin followed by long-term therapy in patients undergoing percutaneous coronary intervention: the PCI-CURE study. Lancet 2001; 358: 527-33.

16. Bhatt DL, Fox KA, Hacke W, Berger PB, Black HR, Boden WE et al. Clopidogrel and aspirin versus aspirin alone for the prevention of atherothrombotic events. N Engl J Med 2006; 354: 1706-17.

17. Bhatt DL, Scheiman J, Abraham NS, Antman EM, Chan FKL, Furberg $\mathrm{CD}$ et al. ACCF/ACG/AHA 2008 expert consensus document on reducing the gastrointestinal risks of antiplatelet therapy and NSAID use: a report of the American College of Cardiology Foundation Task Force on Clinical Expert Consensus Documents. Circulation 2008; 118: 1894-909.

18. Hallas J, Dan M, Andries A, Andersen BS, Aalykke C, Hansen JM et al. Use of single and combined antithrombotic therapy and risk of serious upper gastrointestinal bleeding: population based case- control study. $\mathrm{Br}$ Med J 2006; 333: 726-8

19. Nikolsky E, Stone GW, Kirtane AJ, Dangas GD, Lansky AJ, McLaurin B et al. Gastrointestinal bleeding in patients with acute coronary syndromes: incidence, predictors, and clinical implications: analysis from the ACUITY (Acute Catheterization and Urgent Intervention Triage Strategy) trial. J Am Coll Cardiol 2009; 54: 1293-1302.

20. Ng FH, Wong SY, Lam KF, Chang CM, Lau YK, Chu WM et al. Gastrointestinal bleeding in patients receiving a combination of aspirin, clopidogrel, and enoxaparin in acute coronary syndrome. Am J Gastroenterol 2008; 103: 865-71.

21. Green PJ, Kaplan MM, Curtis LE, Levine PH. Effect of acid and pepsin on blood coagulation and platelet aggregation. A possible contributor to prolonged gastroduodenal haemorrhage. Gastroenterol 1978; 74: 38-43.

22. Hulot JS, Collet JP, Silvain J, Pena A, Bellemain-Appaix A, Barthélémy $\mathrm{O}$ et al. Cardiovascular risk in clopdiogrel treated patients according to cytochrome $\mathrm{P} 450$ 2C19*2 loss-of-function allele or proton pump inhibitor co-administration. J Am Coll Cardiol 2010; 56: 134-50.

23. Gurbel PA, Antonino MJ, Tantry US. Recent developments in clopidogrel pharmacology and their relation to clinical outcomes. Expert Opin Drug Metab Toxicol 2009; 5: 989-1004.

24. Ishizaki T, Horai Y. Cytochrome P450 and the metabolism of proton pump inhibitors-emphasis on rabeprazole. Aliment Pharmacol Ther 1999; 13 (Suppl 3): 27-36.

25. Gurbel PA, Tantry US, Kereiakes DJ. Interaction between clopidogrel and proton-pump inhibitors and management strategies in patients with cardiovascular diseases. Drug Health Patient Saf 2010; 11: 233-6. 